\title{
PENGARUH MODEL PEMBELAJARAN TALKING STICK MENGGUNAKAN MEDIA TONGKAT TERHADAP HASIL BELAJAR MATEMATIKA SISWA SMA
}

\author{
Nursakirah $^{1}$, Mikrayanti $^{2}$, Sowanto $^{*^{2}}$ \\ ${ }^{1}$ Guru Matematika, SMPN 2 Belo \\ ${ }^{2}$ Program Studi Pendidikan Matematika, STKIP Bima
}

*Email korespondensi: sowantos@gmail.com

\begin{abstract}
ABSTRAK
Penelitian ini dilatarbelakangi oleh rendahnya hasil belajar matematika siswa kelas $\mathrm{X}$ salah satu SMA negeri di Kota Bima. Untuk mengatasi hal tersebut, dilakukan penelitian dengan pembelajaran menggunakan model pembelajaran talking stick menggunakan media tongkat. Adapun tujuan dari penelitian ini adalah untuk mengetahui hasil belajar matematika siswa pada materi sistem persamaan linear tiga variable (SPLTV) kelas X salah satu SMA negeri di Kota Bima tahun pelajaran 2020/2021 melalui pengaruh model pembelajaran Talking Stick menggunakan media tongkat. Penelitian ini merupakan quasi eksperimen dengan desain penelitian menggunakan posttest only control design. Adapun populasi dari penelitian ini adalah semua siswa kelas X salah satu SMA Negeri di Kota Bima tahun pelajaran 2020/2021, dengan sampel dalam penelitian ini hanya mengambil dua kelompok yaitu kelompok untuk kelas eksperimen dan kelompok untuk kelas kontrol. Instrumen yang digunakan dalam penelitian ini adalah tes hasil belajar matematika siswa. Analisis data dilakukan secara kuantitatif dengan menggunakan uji-t. Hasil penelitian menunjukkan bahwa penggunaan model pembelajaran talking stick menggunakan media tongkat berpengaruh terhadap hasil belajar siswa pada materi sistem persamaan linear tiga variabel kelas X salah satu SMA negeri di Kota Bima Tahun Pelajaran 2020/2021.
\end{abstract}

Kata kunci: talking stick, hasil belajar matematika, SPLTV.

\begin{abstract}
This research was motivated by the low mathematics learning outcomes of class X students of a public high school in Bima City. To overcome this, a study was conducted using the talking stick learning model using stick media. The purpose of this study was to determine student learning outcomes in the material of three-variable linear equation system (SPLTV) class X one of the public high schools in Bima City for the 2020/2021 academic year through the influence of the Talking Stick learning model using stick media. This research is a quasi-experimental research design using a posttest-only control design. The population of this study were all class X students of one of the public high schools in Bima City for the 2020/2021 academic year, with the sample in this study only taking two groups, namely the experimental class and the control class. The instrument used in this study was a test of student mathematics learning outcomes. The data analysis was performed quantitatively using the t-test. The results showed that the use of the talking stick learning model using stick media had an
\end{abstract}


effect on student learning outcomes in the material of the three-variable linear equation system for class X one of the public high schools in Bima City for the academic year 2020/2021.

Keywords: talking stick, mathematics learning outcomes, SPLTV.

\section{PENDAHULUAN}

Kemajuan suatu bangsa erat kaitannya dengan pendidikan. Tidak heran tujuan pendidikan merupakan usaha sadar dan terencana untuk mewujudkan suasana belajar dan proses pembelajaran agar peserta didik secara aktif mengembangkan potensi dirinya untuk memiliki kekuatan spiritual keagamaan, pengendalian diri, kepribadian, kecerdasan, akhlak mulia, serta keterampilan yang diperlukan dirinya, masyarakat, bangsa dan Negara (Sisdiknas, 2003). Program pendidikan matematika merupakan salah satu usaha dalam rangka memenuhi tujuan pendidikan nasional untuk mencerdaskan kehidupan bangsa dan membangun manusia Indonesia seutuhnya (Kusumah, 2018).

Peranan matematika sebagai ilmu, tidak dapat dipisahkan dari dunia pendidikan yaitu mempunyai peranan yang penting dalam mencetak Sumber Daya Manusia (SDM) yang berkualitas. Hal ini dikarenakan matematika adalah ilmu yang berhubungan dengan penalaran dan pola pikir manusia. Ditinjau dari segi pelaksanaannya, salah satu indikator yang bisa dipakai yaitu hasil survei dilakukan oleh Programe for International Student Assesment (PISA) dari hasil tes dan evaluasi didapatkan bahwa performa pelajar Indonesia pada bidang matematika masih tergolong rendah yaitu peringkat 62 dan 69 negara yang dievaluasi dengan rata-rata 386 point yang termasuk pada kategori rendah dan jauh dari kategori mahir dengan rata-rata 625.

Pembelajaran matematika di Indonesia masih belum sepenuhnya terlaksana dengan baik. Hal ini sesuai dengan yang diungkapkan Sudrijono dalam Puspitarini (2014) bahwa ada beberapa faktor yang mempengaruhi rendahnya nilai matematika siswa Indonesia antara lain adalah siswa menganggap pelajaran matematika sulit, kurangnya minat siswa, kurangnya konsentrasi siswa terhadap mata pelajaran matematika, rendahnya konsep pemahaman siswa dan kurangnya kedisiplinan siswa terhadap pembelajaran matematika. Hal tersebut sejalan dengan pendapat Maulaty (2015) bahwa matematika dianggap sebagai pelajaran yang sulit karena para pelajar sudah menjudge bahwa matematika itu sulit dan rumit karena selalu berhubungan dengan angka, rumus dan hitung-menghitung.

Peran guru sebagai fasilitator menjadi salah satu titik tumpu dalam rangka menyelesaikan permasalahan-permasalahan yang timbul dalam pembelajaran matematika. Di 
era revolusi industri 4.0, kompleksitas dan semakin ketatnya persaingan dunia kerja memberikan tuntutan pada program pendidikan matematika untuk mampu mengembangkan lagi proses melalui kegiatan pembelajaran yang mampu menumbuhkembangkan kemampuan beripikir (Sowanto dkk, 2019). Salah satu cara yang bisa guru lakukan adalah dengan mengkolaborasikan antara model pembelajaran yang biasa digunakan dengan model pembelajaran yang mampu meningkatkan aktivitas dan motivasi siswa, sehingga pembelajaran tidak terkesan monoton dan biasa-biasa saja. Salah satu model pembelajaran yang menarik dan membuat siswa aktif yaitu model pembelajaran kooperatif tipe taking stick menggunakan media tongkat.

Talking stick menggunakan media tongkat termasuk salah satu metode pembelajaran kooperatif. Menurut Kauchak dan Eggen (1993), pembelajaran kooperatif merupakan strategi pembelajaran yang melibatkan siswa untuk bekerja secara kolaboratif dan mencapai tujuan. Model Talking Stick merupakan salah satu model yang menekankan pada keterlibatan peserta didik pada proses belajar mengajar, untuk berani mengemukakan pendapat (Asri, 2015).

Menurut Agus Suprijino (2009) model pembelajaran Talking stick adalah suatu model pembelajaran dengan bantuan tongkat yang lebih mendorong siswa untuk berani mengemukakan pendapat. Lebih lanjut diungkapkan bahwa Model pembelajaran Talking Stick dapat meningkatkan keaktifan siswa dalam proses pembelajaran. Adapun Kelebihan dari model pembelajaran Talking Stick adalah (1) mendorong siswa untuk lebih aktif dalam proses pembelajaran, (2) mendorong siswa untuk tertarik dalam mengikuti proses pembelajaran, dan (3) mendorong siswa untuk berpikir kreatif dan percaya diri dalam mengemukakan pendapat melalui penerapan model pembelajaran Talking Stick diharapkan dapat meningkatkan hasil belajar siswa pada mata pelajaran matematika.

\section{METODE PENELITIAN}

\section{Desain Penelitian}

Penelitian ini dalam pelaksanaannya, dirancang dengan jenis penelitian quasi eksperimen. Penelitian quasi eksperimen dipilih sesuai dengan pendapat Arikunto (2019) bahwa dikatakan quasi eksperimen karena dalam desain ini peneliti tidak dapat mengontrol semua variabel luar yaitu faktor luar yang tidak diteliti dan menjadi pengganggu sehingga 
mempengaruhi jalannya eksperimen. Adapun desain penelitian ini menggunakan posttest only control design.

Dalam desain ini hanya kelompok eksperimen saja yang mandapat perlakuan, dengan tetap observasi dilakukan baik pada kelompok eksperimen maupun kelompok control. Adapun desain penelitian ini mengikuti Sugiono (2009), yaitu sebagai berikut:

\begin{tabular}{|lll|}
\hline $\mathrm{R}_{1}$ & $\mathrm{X}$ & $\mathrm{O}_{1}$ \\
$\mathrm{R}_{2}$ & - & $\mathrm{O}_{2}$ \\
\hline
\end{tabular}

Gambar 1. Desain Penelitian

Keterangan:

$\mathrm{R}_{1} \quad$ : Kelompok Eksperimen

$\mathrm{R}_{2} \quad$ : Kelompok Kontrol

$\mathrm{O} \quad$ : Posttest

X : Perlakuan yang diberikan / Treatment

- $\quad$ : Tidak diberi Perlakuan / Treatment

\section{Populasi dan Sampel Penelitian}

\section{Populasi}

Populasi adalah wilayah generalisasi yang terdiri dari Objek/subjek yang mempunyai kualitas dan karakteristik tertentu yang ditetapkan oleh peneliti untuk dipelajari dan kemudian ditarik kesimpulannya (Sugiyono, 2009). Populasi dalam penelitian ini adalah semua siswa kelas X salah satu SMA Negeri di Kota Bima tahun pelajaran 2020/2021.

\section{Sampel Penelitian}

Sampel penelitian adalah bagian dari jumlah dan karakteristik yang dimiliki oleh populasi (Sugiyono, 2009). Sampel dalam penelitian ini hanya mengambil dua kelompok yaitu kelompok untuk kelas eksperimen dan kelompok untuk kelas kontrol, dengan jumlah siswanya yang sama, atau mendekati dengan teknik pengambilan sampel adalah cluster random sampling yaitu teknik pengambilan sampel untuk menentukan sampel apabila objek yang akan diteliti sangat luas.

\section{Instrumen Penelitian}

Instrumen penelitian adalah alat bantu atau fasilitas yang digunakan oleh peneliti dalam pengumpulan data agar pekerjaannya lebih mudah dan hasilnya lebih baik dalam arti lebih cermat, lengkap dan sistematis sehingga lebih mudah diolah (Arikunto, 2019). 
Dalam penelitian ini, instrumen pembelajaran yang digunakan dalam penelitian ini ada dua yaitu:

Metode Tes

Tes adalah instrumen atau alat untuk mengumpulkan data tentang kemampuan subjek penelitian dengan cara pengukuran. Teknik ini digunakan untuk mengukur kemampuan siswa dalam menguasai materi pelajaran tertentu. Tes hasil belajar yang diberikan berupa pretest yaitu tes yang diberikan sebelum kegiatan pengajaran dan posttest yaitu tes yang diberikan sesudah kegiatan pengajaran. Tes ini memuat tentang materi matriks. Jenis tes ini yang digunakan adalah tes essay/uraian yang terdiri dari 5 soal yang masing-masing soal memperoleh nilai dilihat berdasarkan tingkat kesulitan soal.

\section{Lembar Observasi}

Observasi dengan pengamatan meliputi kegiatan pemuatan perhatian terhadap suatu objek dengan menggunakan seluruh alat indra (pengamatan langsung). Tujuan observasi ini untuk melihat tingkat keaktifan siswa dalam mengikuti proses kegiatan belajar mengajar di dalam kelas. Jadi lembar observasi ini digunakan untuk memperoleh data tentang situasi belajar selama proses pembelajaran berlangsung yang berupa lembar observasi keterlaksanaan pembelajaran dan lembar aktivitas siswa berdasarkan langkah-langkah model pembelajaran yang digunakan.

\section{HASIL DAN PEMBAHASAN}

\section{Hasil Penelitian}

Penelitian ini dilaksanakan di salah satu SMA negeri di Kota Bima mulai bulan September dan berakhir pada bulan November Semester Ganjil Tahun Pelajaran 2020/2021. Pada penelitian ini sampel yang digunakan ada dua yang masing-masing terdiri dari 30 siswa sebagai kelas eksperimen yang diberi perlakuan model pembelajaran Talking stick menggunakan media tongkat dan kelas kontrol yang diberi perlakuan konvesional.

Instrument yang digunakan berupa lembar observasi dan tes essay. Sebelum tes digunakan terlebih dahulu harus diuji untuk mengetahui validitas, reabilitas, daya pembeda dan indeks kesukaran suatu tes. Selanjutnya sampel akan diberikan pretest dan posttest untuk 
mengetahui adanya pengaruh model pembelajaran terhadap hasil belajar siswa melalui uji normalitas, uji homogenitas, dan uji hipotesis.

Adapun hasil dari penelitian ini dapat dilihat sebagai berikut;

\section{Deskripsi Data}

Jumlah siswa kelas eksperimen pada penyelesaian soal pretest sebanyak 30 orang dan penyelesaian pada soal posttest sebanyak 30 orang juga. Adapun tabel data pretest dan posttest nilai rerata, $\mathrm{X}_{\min }, \mathrm{X}_{\max }$, dan nilai varians dari kelas eksperimen adalah seperti tabel di bawah ini.

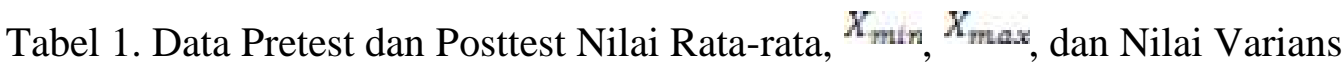

\begin{tabular}{cccccc}
\hline No & Jenis Tes & $\overline{\boldsymbol{X}}$ & $\boldsymbol{X}_{\min }$ & $\boldsymbol{X}_{\max }$ & $\boldsymbol{S}^{\mathbf{2}}$ \\
\hline 1 & Pretest & 37,6 & 30 & 47 & 14,03 \\
2 & Posttest & 72,1 & 60 & 88 & 45,41 \\
\hline
\end{tabular}

Dari tabel distribusi frekuensi dilai pretest dan posttest kelompok eksperimen diatas dapat dilihat bahwa pada soal pretest siswa mendapatkan nilai terendah 30 dan tertinggi 47 , dengan nilai rata-rata 37,6. Sedangkan pada soal posttest siswa mendapatkan nilai terendah 60 dan nilai tertinggi 88 dengan nilai rata-rata 72,1 .

Adapun untuk kelas kontrol, jumlah siswa pada penyelesaian soal pretest sebanyak 31 orang siwa dan penyelesaian pada soal posttest sebanyak 31 orang siswa. Adapun tabel data pretest dan posttest nilai rerata, $\mathrm{X}_{\min }, \mathrm{X}_{\max }$, dan nilai varians dari kelas eksperimen adalah seperti tabel di bawah ini.

Tabel 2. Data Pretest dan Posttest Nilai Rata-rata, $X_{\min }, X_{\max }$, dan Nilai Varians

\begin{tabular}{cccccc}
\hline No & Jenis Tes & $\overline{\boldsymbol{X}}$ & $\boldsymbol{X}_{\min }$ & $\boldsymbol{X}_{\max }$ & $\boldsymbol{S}^{\mathbf{2}}$ \\
\hline 1 & Pretest & 37,9 & 30 & 46 & 18,2 \\
2 & Posttest & 64,2 & 30 & 83 & 184,3 \\
\hline
\end{tabular}

Dari tabel distribusi frekuensi nilai pretest dan posttest kelompok kontrol dapat dilihat bahwa pada soal pretest siswa mendapatkan nilai terendah 30 dan tertinggi 47 dengan nilai rata-rata 37,9 sedangkan pada soal posttest siswa mendapatkan nilai terendah 30 dan nilai tertinggi 83 dengan nilai rata-rata 64,2. 


\section{Analisis Data Posttest Prestasi Belajar Matematis Siswa}

Ada beberapa pengujian yang menjadi prasyarat sebelum data dianalisis yaitu terlebih dahulu dilakukan uji normalitas dan uji homogenitas dalam menentukan uji statistik yang akan digunakan.

\section{Uji Normalitas}

Analisis uji normalitas betujuan untuk mengetahui apakah data berdistribusi normal atau tidak. Dikarenakan jumlah siswa kedua kelas lebih dari 30 orang maka digunakan uji statistik Shapiro-Wilk. Adapun rincian perhitungan posttest dari kedua kelas seperti pada tabel di bawah ini

Tabel 3. Hasil Uji Normalitas Skor Posttest Prestasi Belajar Matematika Siswa

\begin{tabular}{lllll}
\hline No & Kelas & $\chi_{\text {nutung }}^{2}$ & $\chi_{\text {taos }}^{2}$ & Keterangan \\
\hline 1 & Eksperimen & 11,07 & 11,070 & Berdistribusi normal \\
2 & Kontrol & 4,36 & 11,070 & Berdistribusi normal \\
\hline
\end{tabular}

Berdasarkan hasil perhitungan skor kelompok eksperimen membandingkan $\left(\chi_{\text {nteung }}^{2}\right)$ dengan $\left(\chi_{\text {tabel }}^{2}\right)$ dimana $\chi_{\text {tabel }}^{2}$ dilihat dari tabel chi-kuadrat dengan $\mathrm{dk}=\mathrm{k}-1=6-1=5$ pada taraf signifikan $5 \%$ maka didapat $\chi_{\text {tabel }}^{2}=11,070$ dan $\chi_{\text {nutung }}^{2}=11,07$ karena $\chi_{\text {nutung }}^{2} \leq \chi_{\text {tavel }}^{2}$ maka data pretest kelas eksperimen berdistribusi normal sedangkan kelompok kontrol membandingkan $\left(\chi_{\text {nturg }}^{2}\right)$ dengan $\left(\chi_{\text {tabel }}^{2}\right)$ dimana $\chi_{\text {tabel }}^{2}$ dilihat dari tabel chi-kuadrat dengan $\mathrm{dk}=\mathrm{k}-1=6-1=5$ pada taraf signifikan $5 \%$ maka didapat $\chi_{\text {tab }}^{2}$ $=11,070$ dan $\chi_{\text {nutung }}^{2}=4,36$ karena $\chi_{\text {ntung }}^{2} \leq \chi_{\text {tabel }}^{2}$ maka data pretest kelas kontrol berdistribusi normal. Ini berarti bahwa data posttest prestasi belajar matematika siswa siswa yang pembelajarannya dengan talking stick dan pembelajaran dengan kelas konvensional adalah berdistribusi normal.

\section{Uji Homogenitas}

Pada pembahasan uji normalitas diperoleh kesimpulan bahwa data data posttest prestasi belajar matematika siswa siswa pada kedua kelas tersebut adalah berdistribusi normal sehingga perlu dilanjutkan untuk diuji homogenitasnya guna untuk menentukan uji statistik 
selanjutnya. Uji homogenitas merupakan uji yang bertujuan untuk mengetahui apakah suatu varians (keberagaman) data dari dua atau lebih kelompok bersifat homogeny (sama) atau heterogen (tidak sama) menggunakan uji Levene. Adapun rincian perhitungan uji homogenitas seperti pada rangkuman yang terdapat pada tabel di bawah ini

Tabel 4. Hasil Uji Homogenitas Skor Posttest Prestasi Belajar Matematika Siswa

\begin{tabular}{ccccc}
\hline Kelas & Varians & $F_{\text {hitung }}$ & $F_{\text {tabet }}$ & keterangan \\
\hline Eksperimen & 14,023 & \multirow{2}{*}{1,304} & 1,84 & Homogen \\
Kontrol & 18,294 & & & \\
\hline
\end{tabular}

Dari tabel diatas terlihat besar $F_{\text {hitung }}=1,304$ dan $F_{\text {tabel }}=1,84$ dengan varians $\left(S^{2}\right)=14,023$ dan varians kelas kontrol $\left(S^{2}\right)=18,294$ karena $F_{\text {hitung }} S F_{\text {tabel }}$ dengan demikian dapat disimpulkan bahwa data posttest prestasi belajar matematis siswa antara yang pembelajaran dengan talking stick dan pembelajaran dengan kelas konvensional memiliki variansi yang homogen.

\section{Uji Hipotesis}

Berdasarkan uji normalitas dan uji homogenitas kelas eksperimen dengan pembelajaran talking stick dan kelas kontrol dengan pembelajaran konvensional diperoleh kesimpulan bahwa posttest kedua kelas berdistribusi normal dan variansinya homogen. Selanjutnya untuk membuktikan bahwa rerata posttest hasil belajar matematika siswa kelas eksperimen secara signifikan dipengaruhi oleh penerapan pembelajaran dengan talking stick, dilakukan uji menggunakan uji-t. Adapun rincian perhitungan uji-t seperti pada rangkuman yang terdapat pada tabel di bawah ini

\section{Tabel 5. Hasil Uji-t}

\begin{tabular}{rrrr}
\hline $\mathrm{t}$ & $\mathrm{dk}$ & $\mathrm{T}_{\text {tabel }}$ & keterangan \\
\hline 2,86 & 59 & 1,67 & $\mathrm{H}_{0}$ ditolak \\
\hline
\end{tabular}

Harga $t_{\text {hitung }}$ tersebut kemudian dibandingkan dengan harga $t_{\text {tabel }}$ pada taraf signifikan $5 \%$ untuk uji dua pihak dengan $\mathrm{dk}=n_{1}+n_{2}-2=30+31-2=59$, harga $\tau_{\text {tabel }}=$ 1,67. Karena harga $t_{\text {hitung }} \geq \tau_{\text {tabe }}=2,86 \geq 1,67$ maka $H_{0}$. Artinya penggunaan model pembelajaran talking stick menggunakan media tongkat berpengaruh terhadap hasil belajar 
siswa pada materi sistem persamaan linear tiga variabel kelas $\mathrm{X}$ salah satu SMA negeri di Kota Bima Tahun Pelajaran 2020/2021.

\section{Pembahasan}

Penelitian ini menggunakan dua jenis pembelajaran yang dilaksanakan di dua kelas yaitu pada kelas eksperimen dengan model pembelajaran talking stick dan kelas kontrol dengan pembelajaran konvensional. Pada pelaksanaannya, secara umum pembelajaran dengan model pembelajaran talking stick berjalan dengan baik. Berdasarkan hasil penelitian telah diuraikan, bahwa pembelajaran dengan model pembelajaran talking stick berpengaruh secara seignifikan terhadap hasil belajar siswa.

Model pembelajaran talking stick merupakan pembelajaran yang baru bagi siswa SMA Negeri di Kota Bima yang dipilih ini. Sehingga dalam Pelaksanaan pembelajaran dengan menggunakan model pembelajaran talking stick, pada pertemuan pertaman guru menyampaikan mengenai model pembelajaran yang digunakan dalam PBM yaitu model pembelajaran talking stick guru menjelaskan dan memberi tahu langkah-langkah dalam model pembelajaran talking stick selanjutnya guru memberi soal pretest kepada peserta didik dan peserta didik pun menyelesaikan soal pretest tersebut.

Pada pertemuan kedua, tahap awal guru membawa salam, guru mulai mengkondisikan peserta didik untuk belajar, selanjutnya guru melakukan pengulangan materi pada pertemuan sebelumnya, kegiatan inti, guru membagi kelas dalam beberapa kelompok, guru menyiapkan tongkat, guru mulai menjelaskan materi SPLTV dan memberi contoh soal, guru memberi waktu 5 menit kepada peserta didik untuk memahami contoh soal yang dijelaskan, dan guru menyampaikan jika belum ada yang paham silakan bertannya. Sebelum games dimulai guru menyampaikan dalam games ini peserta didik yang mendapat tongkat akan menyelesaikan soal yang ada dalam tongkat tersebut, bisa dibantu oleh anggota kelomponya dan salah satu dari anggota kelompoknya nanti akan mempresentasikan jawaban teman satu kelompoknya. Guru mulai memberikan tongkat tersebut kepada peserta didik (games), pada tahap ini peserta didik sangat bersemangat dalam games tersebut dan menyelesaikan soal.

Dalam model pembelajaran talking stick proses pembelajaran berpusat pada siswa sebagai subjek dalam kegiatan pembelajaran dimana siswa saling bekerja sama dalam kelompok kecil yang tingkat kemampuannya berbeda, dan siswa juga saling aktif dalam mengerjakan soal yang didapat, dan hal ini sejalan dengan pendapat Djamarah dan Zain 
(2006) bahwa siswa dibiasakan hidup bersama, bekerja sama dalam kelompok akan menyadari ada kekurangan dan kelebihan. Hal ini berimplikasi pada pembelajaran dengan model pembelajaran talking stick menggunakan media tongkat berpengaruh secara seignifikan terhadap hasil belajar siswa.

\section{KESIMPULAN}

Berdasarkan rumusan masalah dan hasil penelitian, diperoleh kesimpulan bahwa penggunaan model pembelajaran talking stick menggunakan media tongkat berpengaruh terhadap hasil belajar siswa pada materi sistem persamaan linear tiga variabel kelas X salah satu SMA negeri di Kota Bima Tahun Pelajaran 2020/2021.

\section{REKOMENDASI}

Berdasarkan hasil penelitian, pembahasan, dan kesimpulan dapat dikemukakan rekomendasi agar dalam pelaksanaan pembelajaran dengan talking stick siswa lebih dimotivasi untuk membangun pemahaman konsepnya secara mandiri melalui kerja sama kelompok sehingga dapat mencapai belajar yang memuaskan.

\section{UCAPAN TERIMAKASIH}

Ucapan terima kasih kami sampaikan pada Kepala SMA tempat penelitian serta bapak/ibu dosen STKIP Bima khususnya program studi pendidikan matematika yang telah banyak memberikan masukan dalam pengembangan dan penyelesaian penelitian ini.

\section{REFERENSI}

Asri, B. W., \& Ansori, I. (2015). Peningkatan Kualitas Pembelajaran PKn Menggunakan Model Talking Stick dengan Media Audio-Visual. Joyful Learning Journal, 4(2).

Arikunto, S. (2019). Prosedur penelitian.

Bahri, S. Djamarah dan Aswan zain, 2006. Strategi Belajar Mengajar.

Kauchak, D. P., \& Eggen, P. D. (1993). Learning and teaching. New York: Allyn Bacon, 2(3). 
Kusumah, Y. S. (2018, May). Enhancing students' mathematical representation and selfefficacy through situation-based learning assisted by geometer's sketchpad program. In Journal of Physics: Conference Series (Vol. 1013, No. 1, p. 012107). IOP Publishing.

Rahayu, M. (2015). Mengapa Matematika Dianggap Sulit. Dalam URL: https://www. kompasiana. com/rahayulala/mengapa-matematika-dianggapsulit_54f677b4a33311e6048b4d86 diakses pada tanggal, 10.

Sisdiknas, U. U. (2003). UU RI No. 20 Tahun 2003. Jakarta: Sinar Grafika.

Sowanto, S., Andang, A., Mutmainnah, M., \& Saputra, H. A. (2019). Kemampuan SelfEfficacy Mahasiswa Melalui Bahan Ajar Metode Statistika Menggunakan Hybrid Learning Pada Tantangan Revolusi Industri 4.0. Supermat (jurnal pendidikan matematika), 3(2), 65-73.

Sugiyono, M. P. P., \& Kuantitatif, P. (2009). Kualitatif, dan R\&D, Bandung: Alfabeta. Cet. VII.

Suprijono, A. (2009). Cooperative learning: teori \& aplikasi PAIKEM. Pustaka Pelajar.

Suprijono, A. (2015). Cooperative Learning Teori dan Aplikasi PAIKEM (revisi). Yogyakarta: Pustaka Pelajar. 